\title{
Comparison of Conventional Fractionation and Accelerated Fractionation With Concomitant Boost for Radiotherapy of Non-metastatic Stage IV Head-and-Neck Cancer
}

\author{
CARLOS NARVAEZ ${ }^{1}$, STEVEN E. SCHILD ${ }^{2}$ and DIRK RADES ${ }^{1}$ \\ ${ }^{1}$ Department of Radiation Oncology, University of Lübeck, Lübeck, Germany; \\ ${ }^{2}$ Department of Radiation Oncology, Mayo Clinic, Scottsdale, AZ, U.S.A.
}

\begin{abstract}
Background/Aim: Some patients with unresectable or incompletely resected head-and-neck cancer (SCCHN) cannot tolerate radiochemotherapy. Alternatives are needed that are more effective than conventional radiotherapy alone. Patients and Methods: This retrospective study investigated patients irradiated for non-metastatic stage IV SCCHN who could not receive concurrent chemotherapy. Eight patients received accelerated radiotherapy with concomitant boost (group A) and 31 patients conventionally fractionated radiotherapy (group B). Groups were matched for tumor site, gender, age, performance score and histologic grade. Results: Two-year PFS-rates were $63 \%$ in group A vs. $41 \%$ in group $B$, and median PFS-times were 36 vs. 10 months $(p=0.48)$. Two-year OS-rates were $88 \%$ vs. $37 \%$, and median OS-times were 44 vs. 14 months $(p=0.19)$. Grade $\geq 2$ radiation dermatitis was significantly $(p=0.040)$ more common in group $B$; other toxicities were similar. Conclusion: Accelerated fractionation with concomitant boost appeared superior to conventional fractionation and can be considered for patients with stage IV SCCHN not suitable for radiochemotherapy. Larger studies are needed to confirm these findings.
\end{abstract}

In 2018, head-and-neck cancers were amongst the ten most common primary tumor types worldwide and was estimated to account for approximately 450,000 deaths $(1,2)$. Many patients with locally advanced squamous cell carcinoma of

This article is freely accessible online.

Correspondence to: Professor Dirk Rades, MD, Department of Radiation Oncology, University of Lübeck, Ratzeburger Allee 160, 23538 Lübeck, Germany. Tel: +49 45150045400, Fax: +49 45150045404,e-mail: rades.dirk@gmx.net

Key Words: Head-and-neck cancer, non-metastatic stage IV disease, radiotherapy alone, accelerated fractionation with concomitant boost, conventional fractionation. the head-and-neck (SCCHN) have poor prognoses, particularly if surgical resection of the primary tumor and the loco-regional lymph nodes was not possible or incomplete $(3,4)$. Several randomized trials and a metaanalysis demonstrated significantly better outcomes after definitive radio-chemotherapy for SCCHN when compared to radiotherapy alone (5-7). Patients receiving only an incomplete resection also benefited from concurrent chemotherapy (5). However, since the addition of chemotherapy increases acute toxicity, a considerable number of patients with SCCHN cannot receive it $(8,9)$. For these patients, altered fractionated radiotherapy with a reduced overall treatment time can be a reasonable alternative. According to a meta-analysis of 15 trials of patients with SCCHN, altered fractionation regimens resulted in significantly improved loco-regional control and overall survival (OS) when compared to conventional fractionation $(5 \times 2.0 \mathrm{~Gy}$ per week) (10). One type of altered fractionation is accelerated radiotherapy with concomitant boost. In 2000, a randomized trial showed that accelerated radiotherapy with concomitant boost resulted in better outcomes than conventional fractionation (11). Long-term results of this trial were published in 2014 (12). Although not statistically significant, 5-year reduction in cumulative loco-regional failure was still remarkable for accelerated radiotherapy with concomitant boost (absolute benefit of $6.6 \%$ ) compared to conventional fractionation. In the initial publication of $\mathrm{Fu}$ et $\mathrm{al}$., accelerated fractionation with concomitant boost (72 Gy in 42 fractions over 6 weeks) resulted in higher late toxicity than conventional fractionation (11). In 2001, an alternative concomitant boost regimen (69.9 Gy in 39 fractions over 5.5 weeks) was reported from Germany but not compared to conventional fractionation $(13,14)$. Therefore, the present study was performed to compare accelerated radiotherapy with concomitant boost to conventional fractionation for nonmetastatic stage IV SCCHN in patients unable to receive chemotherapy. 


\section{Patients and Methods}

This retrospective study compared two dose-fractionation regimens of radiotherapy for non-metastatic stage IV SCCHN. The 7th edition of the staging manual of American Joint Committee on Cancer (AJCC) was used, because the human papilloma virus (HPV)-status was not available for most patients included in the study but is required for the classification of oropharynx cancer when using the 8 th edition $(15,16)$. The study was approved by the local Ethics Committee (University of Lübeck, 20-454). Eight selected patients received accelerated radiotherapy with concomitant boost (group A) between 2011 and 2019, and 31 patients were treated with conventionally fractionated radiotherapy (control group B) between 2000 and 2014. Both groups were matched for tumor site (oropharynx $v s$. hypopharynx or larynx), gender (female $v s$. male), age ( $\leq 60 v s .>60$ years), Karnofsky performance score $(60-70 v s$. 80-100) and histologic grade (grade 1-2 vs. 3). The distributions of the characteristics used for matching are summarized in Table I. Fifteen patients received definitive radiotherapy ( 7 in group A and 8 in group B, respectively), and 24 patients (1 in group A and 23 in group B, respectively) adjuvant radiotherapy following incomplete resection of SCCHN. Two patients of group A had received induction chemotherapy with docetaxel. No patient included in this study was considered suitable for concurrent chemotherapy in addition to radiotherapy.

In both groups, radiotherapy was performed on five consecutive days per week (Monday to Friday). In group A, radiotherapy was initially administered to the primary tumor region and loco-regional lymph nodes (high, intermediate and low risk areas) with 2.0 Gy per fraction up to 30.0 Gy (3 weeks). Afterwards, the same treatment volumes received $1.8 \mathrm{~Gy}$ per fraction in the morning for 12 days (cumulative dose $=51.6 \mathrm{~Gy}$ ). After an interval of at least 6 h, 1.5 Gy per fraction was given on the same day to the primary tumor region and high/intermediate risk lymph node areas for 6 days (first concomitant boost, cumulative dose $=60.6 \mathrm{~Gy}$ ), and to the primary tumor region and high-risk lymph node areas for another 6 days (second concomitant boost, cumulative dose $=69.6 \mathrm{~Gy}$ ). The overall treatment time in group A was 5.5 weeks $(13,14)$.

Patients of group B received 2.0 Gy per fraction up to $50.0 \mathrm{~Gy}$ ( 5 weeks) to the primary tumor region and the loco-regional lymph nodes (including high, intermediate and low risk areas), followed by a boost of $10 \mathrm{~Gy}(5 \times 2.0 \mathrm{~Gy}, 1$ week) to the primary tumor region and high/intermediate risk lymph node areas (cumulative dose $=60.0$ Gy). A second boost of 6 or $10 \mathrm{~Gy}(5 \times 2.0 \mathrm{~Gy}, 3$ days or 1 week) was given to the primary tumor region and the high-risk lymph node areas (cumulative dose $=66.0-70.0 \mathrm{~Gy}$ ), resulting in an overall treatment time of 6.5 to 7 weeks.

Both groups were compared with respect to progression-free survival (PFS), which was defined as lack of both loco-regional recurrence and distant metastasis, and overall survival (OS). Both endpoints were referenced from the last day of radiotherapy. Calculations of PFS and OS were performed using the Kaplan-Meier method and the Wilcoxon test. In addition, both groups were compared for acute (oral mucositis, radiation dermatitis) and late (cervical/submental lymph edema, xerostomia) toxicities. These comparisons were performed with the Fisher's exact test. The comparisons with respect to the distribution of the characteristics used for matching were also performed with the Fisher's exact test. For all statistical tests used in this study, $p$-values $<0.05$ were considered significant and $p$-values $<0.20$ were considered showing a trend.
Table I. Comparison of the treatment groups A (accelerated fractionation with concomitant boost) and $B$ (conventional fractionation) with respect to patient characteristics used for matching of the groups. The p-values were obtained from the Fisher's exact test.

\begin{tabular}{|c|c|c|c|}
\hline Characteristic & $\begin{array}{c}\text { Group A } \\
\text { No. of } \\
\text { patients }(\%)\end{array}$ & $\begin{array}{c}\text { Group B } \\
\text { No. of } \\
\text { patients }(\%)\end{array}$ & $p$-Value \\
\hline \multicolumn{4}{|l|}{ Main site of cancer } \\
\hline Oropharynx & $3(37.5)$ & $14(45)$ & \multirow{2}{*}{$>0.99$} \\
\hline Hypopharynx or larynx & $5(62.5)$ & $17(55)$ & \\
\hline \multicolumn{4}{|l|}{ Gender } \\
\hline Female & $2(25)$ & $8(26)$ & \multirow[t]{2}{*}{$>0.99$} \\
\hline Male & $6(75)$ & $23(74)$ & \\
\hline \multicolumn{4}{|l|}{ Age at radiotherapy } \\
\hline$\leq 60$ Years & $2(25)$ & $10(32)$ & \multirow{2}{*}{$>0.99$} \\
\hline$>60$ Years & $6(75)$ & $21(68)$ & \\
\hline \multicolumn{4}{|l|}{ Performance score } \\
\hline KPS $60-70$ & $4(50)$ & $18(58)$ & \multirow[t]{2}{*}{0.71} \\
\hline KPS $80-100$ & $4(50)$ & $13(42)$ & \\
\hline \multicolumn{4}{|l|}{ Histologic grade } \\
\hline Grade $1-2$ & $6(75)$ & $20(65)$ & \multirow{2}{*}{0.69} \\
\hline Grade 3 & $2(25)$ & $11(35)$ & \\
\hline
\end{tabular}

KPS: Karnofsky performance score.

\section{Results}

Median follow-up times were 13 months (range=2-57 months) in the entire cohort, 21.5 months (7-50 months) in group $\mathrm{A}$ and 13 months (range=2-57 months) in group B. When considering only patients who were alive at the last contact, the median follow-up times were 18 months (range=6-51 months), 12 months (10-30 months) and 24 months (range=6-51 months), respectively.

The PFS-rates at 1 year, 2 years and 3 years following radiotherapy were $63 \%, 63 \%$ and $42 \%$, respectively, in group A, and $46 \%, 41 \%$ and $41 \%$, respectively, in group B $(p=0.48$, Table II). Median PFS-times were 36 months in group $\mathrm{A}$ and 10 months in group B. In group A, progression of disease during the follow-up after radiotherapy occurred in five patients. First site of failure was loco-regional recurrence in four patients and distant metastasis in one patient. In group B, 18 patients experienced progression of their disease during the period of follow-up. First site of failure was loco-regional recurrence in nine patients, distant metastasis in eight patients and both (concurrent loco-regional recurrence plus distant metastasis) in one patient.

Death was recorded for four patients of group A and 18 patients of group B. The OS-rates at 1 year, 2 years and 3 years following radiotherapy were $88 \%, 88 \%$ and $88 \%$, respectively, in group A compared to $69 \%, 37 \%$ and $37 \%$, respectively, in group B ( $p=0.19$, Table II). The median OStimes were 44 months in group A and 14 months in group B. 
Table II. Comparison of the treatment groups A (accelerated fractionation with a concomitant boost) and B (standard fractionation) with respect to treatment outcomes in terms of progression-free survival and overall survival. The p-values were obtained from the Wilcoxon test.

\begin{tabular}{lccc}
\hline Outcome & $\begin{array}{c}\text { Group A } \\
(\%)\end{array}$ & $\begin{array}{c}\text { Group B } \\
(\%)\end{array}$ & $p$-Value \\
\hline Progression-free survival & & & \\
At 1 Year & 63 & 46 & 0.48 \\
At 2 Years & 63 & 41 & \\
At 3 Years & 42 & 41 & \\
Overall survival & & & \\
At 1 Year & 88 & 69 & 0.19 \\
At 2 Years & 88 & 37 & \\
At 3 Years & 88 & 37 & \\
\hline
\end{tabular}

When comparing both groups for grade $\geq 2$ toxicities, radiation dermatitis was significantly $(p=0.040)$ more common in group B (Table III). The frequencies of the other investigated toxicities were not significantly different. In group A, all patients received the cumulative dose of 69.6 Gy as planned. In group B, two patients could not receive the second boost due to acute radiation-related toxicity, and the cumulative dose in these patients was $60.0 \mathrm{~Gy}$.

\section{Discussion}

Since outcome of patients with locally advanced SCCHN require improvement, many preclinical and clinical studies have been conducted during recent years (17-22). The prognoses of patients with SCCHN are particularly poor, if unresectable or incompletely resected. Many of these patients receive platin-based radiochemotherapy. In a randomized trial of 100 patients with stage III or IV SCCHN, treatment was 66$72 \mathrm{~Gy}$ (doses per fraction=1.8-2.0 Gy) of radiotherapy alone or the same regimen plus concurrent chemotherapy with cisplatin and 5-fluorouracil (5-FU) (5). Salvage surgery was planned for persistent loco-regional or recurrent disease. Fiveyear loco-regional control rates were $51 \%$ and $62 \%$, respectively $(p=0.04)$, but 5 -year OS rates were not significantly different. In another randomized trial of 226 patients with stage III or IV oropharynx cancer, patients received conventionally fractionated radiotherapy with $70 \mathrm{~Gy}$ in 35 fractions alone or $70 \mathrm{~Gy} / 35$ fractions plus concurrent carboplatin/5-FU (6). The addition of chemotherapy resulted in significantly improved disease-free survival $(p=0.01)$ and loco-regional control $(p=0.002)$ and almost significantly improved OS $(p=0.05)$ at 5 years without significantly increasing toxicity. In another randomized trial of patients with locally advanced larynx cancer, concurrent radiochemotherapy resulted in a significantly higher rate of larynx preservation (23). A meta-analysis of 93 randomized trials demonstrated a
Table III. Comparison of the treatment groups $A$ (accelerated fractionation with a concomitant boost) and B (standard fractionation) with respect to grade $\geq 2$ toxicities. The p-values were obtained from the Fisher's exact test.

\begin{tabular}{llrc}
\hline Toxicity & $\begin{array}{c}\text { Group A } \\
\text { No. of } \\
\text { patients }(\%)\end{array}$ & $\begin{array}{c}\text { Group B } \\
\text { No. of } \\
\text { patients }(\%)\end{array}$ & $p$-Value \\
\hline Grade $\geq 2$ oral mucositis & $8(100)$ & $27(87)$ & 0.56 \\
Grade $\geq 2$ radiation dermatitis & $4(50)$ & $27(87)$ & $\mathbf{0 . 0 4 0}$ \\
Grade $\geq 2$ lymph edema & $2(25)$ & $8(26)$ & $>0.99$ \\
Grade $\geq 2$ xerostomia & $4(50)$ & $13(42)$ & 0.71 \\
\hline
\end{tabular}

Statistically significant $p$-values are shown in bold.

significant benefit in 5-year survival for concurrent radiochemotherapy when compared to radiotherapy alone (7). An additional analysis of 87 randomized trials showed such a benefit for different tumor sites including oral cavity, oropharynx, hypopharynx and larynx (24). Moreover, concurrent chemotherapy (cisplatin) when added to radiotherapy led to improved loco-regional control and diseasefree survival after incomplete resection of SCCHN $(4,8,25)$. Chemotherapy increased the rates of grade $\geq 3$ acute toxicities. In the trial of Bernier et al., these rates were $41 \%$ with vs. $21 \%$ without concurrent chemotherapy $(p<0.001)$, and in the trial of Cooper et al. $77 \%$ (including $1.8 \%$ treatment-related deaths) vs. $34 \%(p<0.001)(8,9)$. Thus, a considerable number of patients cannot tolerate the addition of chemotherapy.

For these patients, alternative strategies are required that result in more favorable outcomes than conventionally fractionated radiotherapy alone. Such options include unconventional fractionation of radiotherapy. In 2000, a randomized trial demonstrated that hyperfractionation $(2 \times 1.2$ Gy per day up to $81.6 \mathrm{~Gy} / 68$ fractions) and accelerated fractionation with concomitant boost ( 72 Gy in 42 fractions over 6 weeks) were superior to conventional fractionation (70 Gy in 35 fractions) with respect to loco-regional control and disease-free survival but not OS (11). In 2006, a meta-analysis found similar results with respect to loco-regional control (10). Moreover, a survival benefit was observed, which was more prominent after hyperfractionation than after accelerated fractionation with concomitant boost $(8 \%$ vs. $2 \%$ absolute benefit at 5 years). However, the authors stated that this difference should be interpreted with caution, since the patient characteristics were different in the two groups (10). An advantage of the concomitant boost regimen is the lower number of fractions, particularly for institutions with a high patient load and or limited capacity at the linear accelerators. After publication of the trial of $\mathrm{Fu}$ et al. (11), other concomitant boost concepts have also been developed (13, 14, 
26-28). In Germany, Staar et al. introduced the regimen, which was also used in the present study (13). According to the results of our study, accelerated fractionation with concomitant boost showed a trend for improved OS and was associated with non-significantly better PFS compared to conventional fractionation without significantly increasing acute and late toxicity. Although statistical significance was not achieved for PFS and OS, the median times were considerably different, i.e. 30 vs. 10 months for PFS and 44 vs. 14 months for OS, respectively. The fact that these differences were not significant can be explained by the small sample size of this study, particularly in the concomitant boost group. This limitation must be considered when interpreting the results. The same applies to other limitations including the retrospective study design, different lengths of follow-up, nonconsideration of the HPV-status, different proportions of patients receiving upfront incomplete resection, and the different treatment periods, during which systemic treatments for recurrent and metastatic SCCHN improved, which likely had an impact on OS. Moreover, two meta-analyses suggested that radiotherapy with accelerated fractionation alone cannot fully compensate the lack of concurrent chemotherapy for treatment of locally advanced SCCHN $(29,30)$.

In summary, accelerated fractionation with concomitant boost provided promising results and appeared superior to conventional fractionation for non-metastatic stage IV SCCHN. This type of fractionation can be considered for selected patients who are not suitable for concurrent radiochemotherapy.

\section{Conflicts of Interest}

The Authors report no conflicts of interest related to the present study.

\section{Authors' Contributions}

The study was designed by C.N. and D.R. Data were collected by C.N. and D.R. and analyzed by S.E.S. and D.R. The article was drafted by D.R. and S.E.S. and approved by all Authors.

\section{References}

1 Chow LQM: Head and neck cancer. N Engl J Med 382: 60-72, 2020. PMID: 31893516 . DOI: 10.1056/NEJMra1715715

2 Bray F, Ferlay J, Soerjomataram I, Siegel RL, Torre LA and Jemal A: Global cancer statistics 2018: GLOBOCAN estimates of incidence and mortality worldwide for 36 cancers in 185 countries. CA Cancer J Clin 68: 394-424, 2018. PMID: 30207593. DOI: $10.3322 /$ caac. 21492

3 Iyer NG, Tan DS, Tan VK, Wang W, Hwang J, Tan NC, Sivanandan R, Tan HK, Lim WT, Ang MK, Wee J, Soo KC and Tan EH: Randomized trial comparing surgery and adjuvant radiotherapy versus concurrent chemoradiotherapy in patients with advanced, nonmetastatic squamous cell carcinoma of the head and neck: 10-year update and subset analysis. Cancer 121: 1599-1607, 2015. PMID: 25639864. DOI: 10.1002/cncr.29251
4 Bernier J, Cooper JS, Pajak TF, van Glabbeke M, Bourhis J, Forastiere A, Ozsahin EM, Jacobs JR, Jassem J, Ang KK and Lefèbvre JL: Defining risk levels in locally advanced head and neck cancers: a comparative analysis of concurrent postoperative radiation plus chemotherapy trials of the EORTC (\#22931) and RTOG (\# 9501). Head Neck 27: 843-850, 2005. PMID: 16161069. DOI: 10.1002/hed.20279

5 Adelstein DJ, Lavertu P, Saxton JP, Secic M, Wood BG, Wanamaker JR, Eliachar I, Strome M and Larto MA: Mature results of a phase III randomized trial comparing concurrent chemoradiotherapy with radiation therapy alone in patients with stage III and IV squamous cell carcinoma of the head and neck. Cancer 88: 876-883, 2000. PMID: 10679658. DOI: 10.1002/ (sici)1097-0142(20000215)88:4<876::aid-cncr19>3.0.co;2-y

6 Denis F, Garaud P, Bardet E, Alfonsi M, Sire C, Germain T, Bergerot $\mathrm{P}$, Rhein B, Tortochaux $\mathrm{J}$ and Calais G: Final results of the 94-01 French Head and Neck Oncology and Radiotherapy Group randomized trial comparing radiotherapy alone with concomitant radiochemotherapy in advanced-stage oropharynx carcinoma. J Clin Oncol 22: 69-76, 2004. PMID: 14657228. DOI: $10.1200 / \mathrm{JCO} .2004 .08 .021$

7 Pignon JP, le Maître A, Maillard E and Bourhis J; MACH-NC Collaborative Group: Meta-analysis of chemotherapy in head and neck cancer (MACH-NC): an update on 93 randomised trials and 17,346 patients. Radiother Oncol 92: 4-14, 2009. PMID: 19446902. DOI: 10.1016/j.radonc.2009.04.014

8 Cooper JS, Pajak TF, Forastiere AA, Jacobs J, Campbell BH, Saxman SB, Kish JA, Kim HE, Cmelak AJ, Rotman M, Machtay M, Ensley JF, Chao KS, Schultz CJ, Lee N and Fu KK; Radiation Therapy Oncology Group 9501/Intergroup: Postoperative concurrent radiotherapy and chemotherapy for high-risk squamouscell carcinoma of the head and neck. N Engl J Med 350: 1937 1944, 2004. PMID: 15128893. DOI: 10.1056/NEJMoa032646

9 Bernier J, Domenge C, Ozsahin M, Matuszewska K, Lefèbvre JL, Greiner RH, Giralt J, Maingon P, Rolland F, Bolla M, Cognetti F, Bourhis J, Kirkpatrick A and van Glabbeke M; European Organization for Research and Treatment of Cancer Trial 22931: Postoperative irradiation with or without concomitant chemotherapy for locally advanced head and neck cancer. N Engl J Med 350: 1945-1952, 2004. PMID: 15128894. DOI: $10.1056 /$ NEJMoa032641

10 Bourhis J, Overgaard J, Audry H, Ang KK, Saunders M, Bernier J, Horiot JC, Le Maître A, Pajak TF, Poulsen MG, O'Sullivan B, Dobrowsky W, Hliniak A, Skladowski K, Hay JH, Pinto LH, Fallai C, Fu KK, Sylvester R and Pignon JP; Meta-Analysis of Radiotherapy in Carcinomas of Head and neck (MARCH) Collaborative Group: Hyperfractionated or accelerated radiotherapy in head and neck cancer: a meta-analysis. Lancet 368: 843-854, 2006. PMID: 16950362. DOI: 10.1016/S01406736(06)69121-6

11 Fu KK, Pajak TF, Trotti A, Jones CU, Spencer SA, Phillips TL, Garden AS, Ridge JA, Cooper JS and Ang KK: A Radiation Therapy Oncology Group (RTOG) phase III randomized study to compare hyperfractionation and two variants of accelerated fractionation to standard fractionation radiotherapy for head and neck squamous cell carcinomas: first report of RTOG 9003. Int J Radiat Oncol Biol Phys 48: 7-16, 2000. PMID: 10924966. DOI: 10.1016/s0360-3016(00)00663-5

12 Beitler JJ, Zhang Q, Fu KK, Trotti A, Spencer SA, Jones CU, Garden AS, Shenouda G, Harris J and Ang KK: Final results of 
local-regional control and late toxicity of RTOG 9003: a randomized trial of altered fractionation radiation for locally advanced head and neck cancer. Int J Radiat Oncol Biol Phys 89: 13-20, 2014. PMID: 24613816. DOI: 10.1016/j.ijrobp.2013.12.027

13 Staar S, Rudat V, Stuetzer H, Dietz A, Volling P, Schroeder M, Flentje M, Eckel HE and Mueller RP: Intensified hyperfractionated accelerated radiotherapy limits the additional benefit of simultaneous chemotherapy - results of a multicentric randomized German trial in advanced head-and-neck cancer. Int J Radiat Oncol Biol Phys 50: 1161-1171, 2001. PMID: 11483325. DOI: 10.1016/s0360-3016(01)01544-9

14 Semrau R, Mueller RP, Stuetzer H, Staar S, Schroeder U, Guntinas-Lichius O, Kocher M, Eich HT, Dietz A, Flentje M, Rudat V, Volling P, Schroeder M and Eckel HE: Efficacy of intensified hyperfractionated and accelerated radiotherapy and concurrent chemotherapy with carboplatin and 5-fluorouracil: updated results of a randomized multicentric trial in advanced head-and-neck cancer. Int J Radiat Oncol Biol Phys 64: 1308-1316, 2006. PMID: 16464538. DOI: 10.1016/j.ijrobp.2005.10.039

15 Edge SB, Byrd DR, Compton CC, Fritz AG, Greene FL and Trotti A (editors): AJCC cancer staging manual (7th ed). New York, NY, Springer, 2010.

16 Amin MB, Edge S, Greene F, Byrd DR, Brookland RK, Washington MK, Gershenwald JE, Compton CC, Hess KR, Sullivan DC, Jessup JM, Brierley JD, Gaspar LE, Schilsky RL, Balch CM, Winchester DP, Asare EA, Madera M, Gress DM and Meyer LR (eds.): AJCC cancer staging manual (8th ed.). New York, NY, Springer, 2017.

17 Loganadane G, Kann BH, Park HS, Johnson SB, Mehra S, Judson BL, Bhatia A, Belkacemi Y, Yarbrough WG, Burtness B and Husain ZA: Clinical outcomes of head and neck cancer patients who undergo resection, but forgo adjuvant therapy. Anticancer Res 39: 4885-4890, 2019. PMID: 31519591. DOI: 10.21873/anticanres.13674

18 Morimoto M, Bijl HP, van der Schaaf A, Xu CJ, Steenbakkers RJHM, Chouvalova O, Yoshioka Y, Teshima T and Langendijk JA: Development of normal tissue complication probability model for trismus in head and neck cancer patients treated with radiotherapy: The role of dosimetric and clinical factors. Anticancer Res 39: 6787-6798, 2019. PMID: 31810944. DOI: 10.21873/anticanres.13894

19 Grehn M, Stille M, Ziemann C, Cremers F, Rades D and Buzug TM: A new phantom for individual verification of the dose distribution in precision radiotherapy for head-and-neck cancer. Anticancer Res 39: 6931-6938, 2019. PMID: 31810964. DOI: 10.21873/anticanres.13914

20 Iijima Y, Bandow K, Sano M, Hino S, Kaneko T, Horie N and Sakagami H: In vitro assessment of antitumor potential and combination effect of classical and molecular-targeted anticancer drugs. Anticancer Res 39: 6673-6684, 2019. PMID: 31810932. DOI: 10.21873 /anticanres.13882

21 Moro Y, Kogashiwa Y, Sakurai H, Takahashi R, Kimura T, Hirasaki M, Matsumoto $\mathrm{Y}$, Sugasawa $\mathrm{M}$ and Kohno N: In vitro study of the anti-cancer effect of alternate-day 5-fluorouracil in head and neck cancer cells. Anticancer Res 39: 6041-6047, 2019. PMID: 31704830. DOI: 10.21873/anticanres.13810

22 Matsunaga N, Wakasaki T, Yasumatsu R and Kotake Y: Long noncoding RNA, ANRIL, regulates the proliferation of head and neck squamous cell carcinoma. Anticancer Res 39: 4073-4077, 2019. PMID: 31366490. DOI: 10.21873/anticanres.13564
23 Forastiere AA, Zhang Q, Weber RS, Maor MH, Goepfert H, Pajak TF, Morrison W, Glisson B, Trotti A, Ridge JA, Thorstad W, Wagner H, Ensley JF and Cooper JS: Long-term results of RTOG 91-11: a comparison of three nonsurgical treatment strategies to preserve the larynx in patients with locally advanced larynx cancer. J Clin Oncol 31: 845-852, 2013. PMID: 23182993. DOI: $10.1200 / J C O .2012 .43 .6097$

24 Blanchard P, Baujat B, Holostenco V, Bourredjem A, Baey C, Bourhis J and Pignon JP; MACH-CH Collaborative group: Metaanalysis of chemotherapy in head and neck cancer (MACH-NC): a comprehensive analysis by tumour site. Radiother Oncol 100: 3340, 2011. PMID: 21684027. DOI: 10.1016/j.radonc.2011.05.036

25 Cooper JS, Zhang Q, Pajak TF, Forastiere AA, Jacobs J, Saxman SB, Kish JA, Kim HE, Cmelak AJ, Rotman M, Lustig R, Ensley JF, Thorstad W, Schultz CJ, Yom SS and Ang KK: Long-term follow-up of the RTOG 9501/intergroup phase III trial: postoperative concurrent radiation therapy and chemotherapy in high-risk squamous cell carcinoma of the head and neck. Int J Radiat Oncol Biol Phys 84: 1198-1205, 2012. PMID: 22749632. DOI: $10.1016 /$ j.ijrobp.2012.05.008

26 Ghoshal S, Goda JS, Mallick I, Kehwar TS and Sharma SC: Concomitant boost radiotherapy compared with conventional radiotherapy in squamous cell carcinoma of the head and neck a phase III trial from a single institution in India. Clin Oncol (R Coll Radiol) 20: 212-220, 2008. PMID: 18343310. DOI: 10.1016/j.clon.2008.01.011

27 Kubes J, Cvek J, Vondracek V, Pala M and Feltl D: Accelerated radiotherapy with concomitant boost technique $(69.5 \mathrm{~Gy} / 5$ weeks): an alternative in the treatment of locally advanced head and neck cancer. Strahlenther Onkol 187: 651-655, 2011. PMID: 21947124. DOI: $10.1007 / \mathrm{s} 00066-011-2246-2$

28 Skladowski K, Hutnik M, Wygoda A, Golen M, Pilecki B, Przeorek W, Rutkowski T, Lukaszczyk-Widel B, Heyda A, Suwinski R, Tarnawski R and Maciejewski B: Radiation-free weekend rescued! Continuous accelerated irradiation of 7-days per week is equal to accelerated fractionation with concomitant boost of 7 fractions in 5-days per week: report on phase 3 clinical trial in head-and-neck cancer patients Int J Radiat Oncol Biol Phys 85: 741-746, 2013. PMID: 22836063. DOI: 10.1016/j.ijrobp.2012.06.037

29 Gupta T, Kannan S, Ghosh-Laskar S and Agarwal JP: Systematic review and meta-analysis of conventionally fractionated concurrent chemoradiotherapy versus altered fractionation radiotherapy alone in the definitive management of locoregionally advanced head and neck squamous cell carcinoma. Clin Oncol (R Coll Radiol) 28: 50-61, 2016. PMID: 26454839. DOI: 10.1016/j.clon.2015.09.002

30 Lacas B, Bourhis J, Overgaard J, Zhang Q, Grégoire V, Nankivell M, Zackrisson B, Szutkowski Z, Suwiński R, Poulsen M, O'Sullivan B, Corvò R, Laskar SG, Fallai C, Yamazaki H, Dobrowsky W, Cho KH, Beadle B, Langendijk JA, Viegas CMP, Hay J, Lotayef M, Parmar MKB, Aupérin A, van Herpen C, Maingon P, Trotti AM, Grau C, Pignon JP and Blanchard P; MARCH Collaborative Group: Role of radiotherapy fractionation in head and neck cancers (MARCH): an updated meta-analysis Lancet Oncol 18: 1221-1237, 2017. PMID: 28757375. DOI: $10.1016 / \mathrm{S} 1470-2045(17) 30458-8$

Received November 19, 2020

Revised November 26, 2020

Accepted November 27, 2020 